\title{
Forensic Anthropology A Journal for our Discipline
}

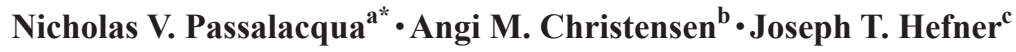

\section{Overview and Scope of the Journal}

Welcome to Forensic Anthropology, the only journal devoted to the advancement of the science and professional development of the fields of forensic anthropology and forensic archaeology. Forensic Anthropology is an inclusive venue created to foster professional discussions about research, policy, and the application of forensic anthropology globally. Issues will (at least initially) be published quarterly and available in electronic and print format. Subscription information, submission instructions, and other details can be found on the journal's website: http://journals.upress.ufl.edu/fa.

Although forensic anthropology is typically defined as the application of (primarily biological) anthropological methods and theory to medicolegal contexts, the modern application of forensic anthropology is both anthropologically holistic and interdisciplinary in nature. The field encompasses methodological and theoretical aspects of biological anthropology as well as archaeology and sociocultural anthropology. Many of the current methods used in forensic anthropology stem not only from the anthropological sciences, but also from chemistry, engineering, biomechanics, biology, and other natural and social sciences. Moreover, the scope and application of forensic anthropology is increasingly broad. While forensic anthropological casework most

\footnotetext{
${ }^{\mathrm{a}}$ Anthropology and Sociology Department, Western Carolina University, Cullowhee, NC 28723, USA

${ }^{b}$ Federal Bureau of Investigation Laboratory, Quantico, VA 22135, USA

${ }^{\mathrm{c}}$ Department of Anthropology, Michigan State University, East Lansing, MI 48823, USA

*Correspondence to: Nicholas V. Passalacqua, Anthropology and Sociology Department, Western Carolina University, Cullowhee, NC 28723, USA

E-mail: passala5@gmail.com

Disclaimer: The views expressed are those of the authors and do not necessarily reflect the official policy or position of the FBI. Names of commercial manufacturers are provided for identification purposes only, and inclusion does not imply endorsement of the manufacturer or its products or services by the FBI.
}

often involves the analysis of unidentified skeletal remains and skeletal trauma in a medicolegal context, it is also applied in contexts beyond traditional medicolegal questions, including addressing legal claims related to the remains of native populations and resolving humanitarian investigations such as war crimes and mass disasters. In recent years there has been growth in educational programs dedicated to forensic anthropology. This has prompted a significant increase in research and the number of publications in the field, with articles appearing in a wide variety of periodicals and edited volumes related to forensic science, anthropology, medicine, anatomy, and imaging, among others.

Given the broad scope and academically prolific nature of modern forensic anthropology, a scholarly venue is needed that embraces and caters to this holistic, multidisciplinary, and research-rich field. Journals focused primarily on anthropology or forensic science are insufficient to meet the needs of the discipline, and the publication of relevant research in numerous (and sometimes disparate) journals makes it challenging to stay abreast of the latest developments, requiring professionals to locate, maintain subscriptions to, and routinely review a wide variety of scholarly journals. Forensic Anthropology therefore aims to be an inclusive and centralized venue, emphasizing research and technical advancements related to all facets of forensic anthropology. Topics of interest for this journal include osteology, skeletal biology, modern human skeletal variation, and forensic archaeology, though contributions in any area that promote, advance, or enhance the field will be considered. The instructive quality of case studies is recognized, and we therefore encourage the submission of case reports with academic or educational merit. The journal will also publish relevant book reviews and consider pertinent review articles.

We are dedicated to high-quality content and a rigorous review process. All reviews are double-blind, meaning reviewers are blinded to the manuscript author, and authors are blinded to the reviewers. This process ensures that reviews are fair, with minimal bias. While performing peer reviews can 
be time consuming and tedious, it is a very important part of the scientific publication process, and we encourage our colleagues to assist in these reviews. We aim to maintain a repository of professionals interested in, and dedicated to, high-quality reviews, and anyone interested in serving as a reviewer is encouraged to contact the editors. We are also committed to ethical publishing standards; authors and reviewers must adhere to the ethics in publishing guidelines put forth by the Committee on Publication Ethics (COPE 2017).

\section{The Editorial Board and Organizational Partners}

The inaugural editors of Forensic Anthropology are Nicholas Passalacqua, Angi Christensen, and Joseph Hefner, who several years ago began discussing a possible journal with colleagues and researching potential publishers based on the perceived need for a venue dedicated to the discipline. This was largely the result of frustration with currently available venues, combined with the recognition of the large number of forensic anthropology papers published annually. To facilitate the journal's success, and to demonstrate its aim of inclusiveness, organizational partners were invited to assist in supporting, representing, and promoting the journal. Current organizational partners include the American Board of Forensic Anthropology (ABFA), the Asociación Latinoamericana de Antropología Forense (ALAF), and the Society of Forensic Anthropologists (SOFA). Organizational partners have representation on the Forensic Anthropology editorial board and receive subscription and promotion benefits. We thank them for their support. In addition, an editorial board comprised of associate editors was selected to represent the diverse specialties, interests, workplaces, and geography of forensic anthropological practice. The current editorial board includes: Gregory Berg (book review editor), Popi Chrysostomou, Christian Crowder, Derek Congram, Paul Emanovsky, Michael Kenyhercz, Alexandra Klales, Jennifer Love, James Pokines (ABFA representative), Brian Spatola (SOFA representative), M. Kate Spradley, Carl Stephan, and Ivana Wolff (ALAF representative). We welcome the assistance of our colleagues in making Forensic Anthropology a success, and encourage participation and feedback. Please contact the editors or a member of the editorial board with any questions.

\section{Impact Factor}

We recognize the importance to some of our colleagues (and/ or their employers) of publishing in a journal with a high impact factor. The impact factor of a journal (which was originated by Eugene Garfield in the mid-1900s [Garfield 2006]) is a metric used (ostensibly) to assess a journal's relative importance or contribution to a field of study. The overall importance and relevance of a journal's impact factor is a matter of some debate. Because a journal's impact factor is a function of citations to all articles published in a journal, it does not reflect the quality of any specific article or author (The PLoS Medicine Editors 2006). Moreover, a journal's impact factor can be easily skewed by one or two highly cited articles, and journals that publish larger quantities of articles may have lower impact factors than journals that publish fewer articles (Campbell 2008). An impact factor does not reflect how well read a journal is or its influence on policy (The PloS Medicine Editors 2006). Therefore many feel that impact factors are given too much weight considering they do not actually measure the importance of a journal or the impact it has on a discipline. Others have suggested that perhaps such assessments should be adjusted to account for variables such as specialty, citation density, and half-life (Garfield 2006). A journal's impact factor for a given year is calculated as the citations during that year (published in journals indexed in Clarivate Analytics' Web of Science) to all articles published by the journal in the previous two years, divided by number of articles published in the journal in the previous two years deemed to be "citable" by Clarivate Analytics.

Despite limitations, the influence of impact factors on authors is recognized, and we therefore wanted to address this topic with our readership. Given that the first issue of Forensic Anthropology is being published in 2018, it will be eligible for an impact factor after the year 2020. The impact factor for 2020 will be calculated as the number of published citations in 2020 to all articles published in Forensic Anthropology in 2018-2019, divided by the number of citable articles published by Forensic Anthropology in 2018-2019. Examples of recent impact factors related to forensic anthropology are provided below (2016 Journal Citation Reports ${ }^{\mathbb{C}}$ ).

Journal of Forensic Sciences: 1.127

Forensic Science International:

1.336

American Journal of Physical Anthropology: $\quad 2.552$

International Journal of Osteoarchaeology: $\quad 1.038$

Journal of Anatomy: $\quad 2.182$

Journal of the American Medical Association: 37.684

\section{Looking Forward}

It is with great pleasure that we introduce this new journal, and we appreciate the support and enthusiasm we have already received from many of our colleagues. We look forward to the continued success of Forensic Anthropology, knowing that it will depend on support from the forensic anthropological community. We thank our current contributors, reviewers, and associated editors, and we look forward to many more issues of Forensic Anthropology. 


\section{References}

2016 Journal Citation Reports. ${ }^{(}{ }^{\circ}$ Clarivate Analytics; 2017.

Campbell P. Escape from the impact factor. Ethics in Science and Environmental Politics 2008;8(1):5-7.

Committee on Publication Ethics (COPE). http://publicationethics .org/. Accessed August 23, 2017.
Garfield E. The history and meaning of the journal impact factor. Journal of the American Medical Association 2006;295(1): 90-93.

The PLoS Medicine Editors. The impact factor game. PLoS Medicine 2006;3(6):0707-0708. 